\title{
Spiritual Well-being, Attitude, Involvement, Perceptions and Competencies: Measuring the Self-Perception of Nursing Students During 2018, 2019 and the First Wave of COVID-19 in 2020
}

\author{
Cornelia Brandstötter ${ }^{1}$ \\ Institute of Nursing and Practice, Paracelsus Medical University, Salzburg, Austria \\ Email: c.brandstoetter@pmu.ac.at
}

\author{
Firuzan Sari Kundt ${ }^{2}$ \\ Institute of Nursing and Practice, Paracelsus Medical University, Salzburg, Austria \\ Email: firuzan.sari@pmu.ac.at
}

\section{Piret Paal ${ }^{3}$}

Institute of Nursing and Practice, Paracelsus Medical University, Salzburg, Austria Email: piret.paal@pmu.ac.at

\begin{abstract}
Developing spirituality and spiritual care competencies in nursing students is an important task. In German-speaking countries, research investigating spiritual care in nursing teaching and nursing practice is limited. The aim of this study was to measure nursing students' perceptions of their spiritual care competencies, care attitudes, involvement, perception and well-being. Three groups of second-year undergraduate nursing students in the years 2018, 2019 and 2020 participated in a cross-sectional
\end{abstract}

1. Cornelia Brandstötter, MA, is a Research Associate at the Institute of Nursing Science and Practice, Paracelsus Medical University, Salzburg, Austria.

2. Firuzan Sari Kundt, MPH, MA, is a Research Associate at the Institute of Nursing Science and Practice, Paracelsus Medical University, Salzburg, Austria.

3. Priv.-Doz. Dr. Piret Paal, PhD, MA, BA, is a Reader in Nursing Science (Palliative Care) at the Institute of Nursing Science and Practice, Paracelsus Medical University, Salzburg, Austria. 
study using validated scales to measure students' spiritual well-being (JAREL), spiritual care attitudes and involvement (SAIL), spirituality and spiritual care perceptions (SSCRS), and competencies (SCCS). Nursing students $(\mathrm{N}=191)$ show a high level of spiritual attitude and involvement. The groups attained similar scores on the SSCRS, but the group of 2020 achieved the highest score, indicating a broader view of spirituality. This group also scored highest on the SCCS, which shows a higher self-perceived competence in delivering spiritual care. At the same time, the 2020 group reported significantly low spiritual well-being scores. Students rated their competencies in delivering spiritual care as high. This may be negatively affected if their spiritual well-being remains low. Further investigation is needed to clarify how to tackle this shortcoming in educational training.

Keywords: spirituality, spiritual care, spiritual well-being, self-assessment, COVID-19, nursing, nursing education, Austria

Zusammenfassung (Deutsch): Die Entwicklung eines Verständnisses für Spiritualität und weiteren spirituellen Pflegekompetenzen bei Pflegestudierenden ist eine wichtige Aufgabe. Im deutschsprachigen Raum ist jedoch die Forschung, die Spiritual Care in der Pflegeausbildung und Pflegepraxis untersucht, begrenzt. Das Ziel dieser Studie ist die Wahrnehmung von Pflegestudierenden hinsichtlich ihrer spirituellen Pflegekompetenzen, ihrer Pflegeeinstellungen, ihres Engagements, ihrer Wahrnehmung und ihres Wohlbefindens zu messen. Wir untersuchten drei Gruppen von Pflegestudierenden im zweiten Studienjahr in den Jahren 2018, 2019 und 2020, im Rahmen einer Querschnittsstudie, unter Verwendung validierter Skalen zur Messung des spirituellen Wohlbefindens (JAREL), der Einstellungen und des Engagements in der Spiritual Care (SAIL), der Wahrnehmung von Spiritualität und Spiritual Care (SSCRS) und der Kompetenzen (SCCS) der Studierenden. Die Pflegestudierenden (N = 191) zeigen ein hohes Maß an spiritueller Einstellung und Engagement. Alle drei Gruppen bekamen zwar ähnliche Punktzahlen auf dem SSCRS, aber die Gruppe der 2020er erreichte die höchste Punktzahl, was auf eine umfangreichere Sichtweise der Spiritualität hinweist. Diese Gruppe erzielte auch die höchste Punktzahl beim SCCS, was auf eine stark positive Eigenwahrnehmung der spirituellen Kompetenzen hinweist. Gleichzeitig gab die 2020er-Gruppe signifikant niedrige Werte für ihr spirituelles Wohlbefinden an. Die Studierenden schätzen ihre Kompetenz, Spiritual Care zu leisten, als hoch ein. Leider kann sich das negativ auswirken, solange ihr spirituelles Wohlbefinden niedrig bleibt. Weitere Untersuchungen sind erforderlich, um zu klären, wie diese Lücke in der Ausbildung geschlossen werden kann.

Schlagworte: Spiritualität, Spiritual Care, spirituelles Wohlbefinden, Selbsteinschätzung, COVID-19, Pflege, Pflegeausbildung, Österreich

\section{Introduction}

Spirituality - a unique pursuit of meaning-making within a personal belief system - has been identified as a vital dimension of an individual's 
health (Chuengsatiansup, 2003), and thus, spirituality should be an integral component of nursing assessment and nursing practice (ICN, 2012). The European Spiritual Care Education Standard for undergraduate nurses and midwives describes spirituality as "the dynamic dimension of human life that relates to the way persons (individual and community) experience, express and/or seek meaning, purpose and transcendence, and the way they connect to the moment, to self, to others, to nature, to the significant and/ or the sacred" (EPICC, 2019).

The concept of spiritual care in nursing has been defined via the following attributes: healing presence, therapeutic use of self, intuitive sense, exploration of the spiritual perspective, meaning-centred therapeutic intervention, patient-centredness, the documentation and evaluation of spiritual care and creation of a spiritually nurturing environment (Ghorbani et al., 2021; Ramezani et al., 2014). Based on 151 articles and seven books, Ramezani and colleagues demonstrated that "the delivery of spiritual care leads to positive consequences such as healing, promotion of spiritual wellbeing, psychological adaptation and feelings of satisfaction for patients, and promotion of spiritual awareness and job satisfaction for nurses" (Ramezani et al., 2014).

There is empirical evidence that the ability to demonstrate spirituality in the workplace has positive effects on "job commitment, satisfaction, and performance; demonstrating results in altruism and conscientiousness, selfcareer management, reduced inter-role conflict, reduced frustration, organization based self-esteem, involvement, retention, and ethical behaviour" (Paal et al., 2018). These findings indicate that enhancing spirituality and spiritual care competencies promotes nurses' overall well-being, and hence, facilitates patients' safety, well-being and satisfaction. Spiritual care training enhances not only spirituality on an individual level but also in clinical practice. Studies indicate that there is a rise in regular calls to chaplains and increased reporting of spiritual distress (Paal, Helo \& Frick, 2015a).

A recent scoping review on spiritual care in nursing science demonstrated that "there is a strong contrast between national and international development: empirical studies in German language are simply lacking" (Peng-Keller \& Rettke, 2017). Peng-Keller and Rettke have pointed out that

in the face of globalisation, introducing new spiritual care models will be a challenge for German-speaking nursing as the scope of questions to be solved is extensive, beginning from defining the profession specific competencies, establishing the assessment and documentation instruments, as well as developing appropriate educational programs. (Peng-Keller \& Rettke, 2017) 
This article attempts to fill some of the knowledge gaps by presenting the results of fostering spirituality and spiritual care competencies in undergraduate nursing students in Salzburg, Austria.

\section{Background}

In June 2018, June 2019 and May 2020, a single six-hour lecture entitled "Spirituality and spiritual care in nursing" was included in the curriculum of second year Bachelor-level nursing students in Salzburg, Austria. The session concentrated on the theoretical aspects of spirituality, such as definitions, and its importance for health and nursing practice. The lecture consisted of a brief introduction about international activities, in order to demonstrate that spirituality is an internationally acknowledged field in nursing. To keep the lesson interactive, students were given an opportunity to share their opinions on the importance of spiritual care in nursing via online voting. In the afternoon session, students were divided into small groups and invited to write short wikis on preselected topics and literature. A section for self-reflection was provided using a specially designed questionnaire. In 2018 and 2019, the sessions took place in the classroom, but in 2020 the whole session was taught online due to the COVID-19 pandemic. Hence, the paper questionnaire about self-reflection was provided online, which differed from previous years.

\section{Aims of the Study}

This quantitative cross-sectional study focuses on the results of nursing students' spiritual well-being, attitude, involvement, perceptions and competencies.

\section{Method}

We used a questionnaire from earlier international studies measuring spirituality and spiritual care competencies in undergraduate nurses (Ross et al., 2014, 2016, 2018). The authors' permission was obtained (EPICC, 2019). This questionnaire contains demographics and validated scales to measure spiritual well-being (JAREL) (Hungelmann et al., 1996), spiritual care attitudes and involvement (SAIL) (Meezenbroek \& Garssen, 2008), spirituality and spiritual care perceptions (SSCRS) (McSherry, Draper \& Kendrick, 2002) and competencies (SCCS) (van Leeuwen et al., 2009). 


\section{Ethics Approval}

We applied for ethics approval from the Ethics Committee in Salzburg, Austria. Due to the research design, the Ethics Committee deemed the study exempt from requiring ethical approval. Following ethical guidelines, participation was voluntary and data were anonymized, making individual identification impossible. Confidentiality was applied at all stages of the research process.

\section{Sample}

In 2018, 77 of 107 students who attended the "Spirituality and spiritual care in nursing" lecture completed the questionnaire. The completion rate in 2019 was 56 students out of 108, and in 2020, 58 of 113 students completed the questionnaire. We removed all incomplete data sets. In total, we included 191 questionnaires in the final analysis.

\section{Data Collection}

In June 2018 and 2019, the questionnaire was handed out to all attendees in print format during the "Spirituality and spiritual care in nursing" lecture. In May 2020, the survey tool EvaSys was used to create an online version of the questionnaire. We sent an email with the request to participate to attendees of the online lecture. The adaptation of the research design (from print to online version) and the lecture (from presence to online) was necessary due to the COVID-19 pandemic. The first part of the questionnaire, in both print and digital versions, contains demographic data, students' positive and negative life events, and spiritual practices. The second part includes validated self-assessment scales to measure students' perception of their spiritual well-being (JAREL) (Hungelmann et al., 1996), spiritual care attitudes (SAIL) (Meezenbroek \& Garssen, 2008), perceptions (SSCRS) (McSherry, Draper \& Kendrick, 2002) and competencies (SCCS) (van Leeuwen et al., 2009).

\section{JAREL}

The JAREL Spiritual Well-Being Scale (Hungelmann et al., 1996) was specially developed for the field of nursing. It contains 21 items scored from 1 (strongly disagree) to 6 (strongly agree). Possible scores range from 21 to 126 , with higher scores indicating better spiritual well-being. The questionnaire measures three different levels of well-being: low (0-50), medium (51-84), and high (85-126). It includes existential as well as religious aspects of spirituality (Ross et al., 2014). 
SAIL

The Spiritual Attitude and Involvement List from Meezenbroek and associates (2008) contains 26 items scored from 1 to 6 , where higher scores indicate higher levels of spiritual attitude/involvement, with 156 as the highest achievable score. A mean SAIL score $>4$ indicates high spiritual attitude/ involvement (Ross et al., 2014).

\section{SSCRS}

The Spirituality and Spiritual Care Rating Scale (McSherry, Draper \& Kendrick, 2002) measures students' perceptions of spirituality and spiritual care. It is a valid and reliable questionnaire that has already been used in many studies (Ross et al., 2014, 2018). It is scored from 1 (strongly disagree) to 5 (strongly agree): "A high overall score indicates a broader view of spirituality (...) and spiritual care" (Ross et al., 2014, p. 699).

\section{SCCS}

The Spiritual Care Competency Scale (van Leeuwen et al., 2009) is a validated and reliable questionnaire measuring students' self-perception regarding their competence in delivering spiritual care. Its 27 items are scored from 1 (completely disagree) to 5 (fully agree), with a total possible score ranging from 27 to 135 . Any sum score that exceeds 3.5 is considered to indicate increased perceived spiritual competency (Ross et al., 2014). In former studies, Cronbach's alpha domains reach anywhere from 0.56 to 0.82 (Ross et al., 2014). "The SCCS can be employed as a continuous measure of competency ranging from 1 to 5 with higher scores indicating higher levels of perceived competency or it can be employed as a binary variable whereby competency is indicated by a mean SCCS score across all questions $>3.5$ " (Ross et al., 2014, p. 699).

\section{Data Analysis}

The statistical software program IBM SPSS 27 was used for statistical analysis. Descriptive statistics were computed on demographic variables, students' positive and negative life events, and their spiritual practices.

For each self-assessment scale (JAREL, SAIL, SCCS, SSCRS), reliability analyses were conducted to compare with international data. Mean scale scores and sum scores for the four self-assessment tools were also computed. The results of the three groups of undergraduate nursing students (2018, $2019,2020)$ were compared with each other and with international data. 


\section{Results}

\section{Demographic Data}

Most of the students in 2018, 2019 as well as 2020 were female (2018, 91\%; 2019, 91.1\%; 2020, 89.7\%) and between 21 and 25 years old (2018, 87\%; 2019, $94.6 \% ; 2020,87.9 \%)$. A total of $58.4 \%$ of the students from the 2018 group had already gained working experience in a healthcare setting. This percentage was higher for the 2019 group (72.5\%), but lower for the 2020 group (43.1\%). In all three groups, the main "life view" was Christian (2018, 83\%; $2019,72.7 \%$; 2020, 75.9\%), followed by atheist (2018, 6.5\%; 2019, 12.7\%; 2020, 5.3\%). In 2018, 2019 and 2020, 4\%, 3.6\% and $0 \%$ of students respectively described themselves as humanists. Table 1 shows all the demographic data results.

Table 1

Demographic data

\begin{tabular}{llll}
\hline Gender & 2018 & 2019 & 2020 \\
\hline Female & $91 \%(n=70)$ & $91.1 \%(n=51)$ & $89.7 \%(n=52)$ \\
Male & $9 \%(n=7)$ & $8.9 \%(n=5)$ & $10.3 \%(n=6)$ \\
Inter ${ }^{\star}$ other & - & - & - \\
\hline Age & 2018 & 2019 & 2020 \\
\hline Up to 20 & $4 \%(n=3)$ & - & $1.7 \%(n=1)$ \\
$21-25$ & $87 \%(n=67)$ & $96.4 \%(n=54)$ & $87.9 \%(n=51)$ \\
$26-30$ & $9 \%(n=7)$ & $3.6 \%(n=2)$ & $10.3 \%(n=6)$ \\
\hline Working experience in & & & \\
healthcare setting & 2018 & 2019 & 2020 \\
\hline Yes & $58.4 \%(n=45)$ & $72.5 \%(n=29)$ & $43.1 \%(n=25)$ \\
No & $41.6 \%(n=32)$ & $27.5 \%(n=11)$ & $56.9 \%(n=33)$ \\
\hline Life view & 2018 & 2019 & 2020 \\
\hline Christian & $83 \%(n=64)$ & $72.7 \%(n=40)$ & $75.9 \%(n=44)$ \\
Atheist & $6.5 \%(n=5)$ & $12.7 \%(n=7)$ & $5.3 \%(n=3)$ \\
Humanist & $4 \%(n=3)$ & $3.6 \%(n=2)$ & - \\
Hindu & - & $1.8 \%(n=1)$ & - \\
Sikh & - & $1.8 \%(n=1)$ & - \\
Buddhist & $1.3 \%(n=1)$ & $1.8 \%(n=1)$ & $3.4 \%(n=2)$ \\
Muslim & $1.3 \%(n=1)$ & $1.8 \%(n=1)$ & $1.7 \%(n=1)$ \\
Agnostic & $1.3 \%(n=1)$ & $3.6 \%,(n=2)$ & $3.4 \%(n=2)$ \\
Greek Orthodox & - & - & - \\
Other & $1.3 \%(n=1)$ & $3.6 \%(n=2)$ & $10.3 \%(n=6)$ \\
\hline & & &
\end{tabular}




\section{Spiritual Practices}

The percentage of daily spiritual practices during the COVID-19 lockdown in 2020 increased in almost every category (practise prayer, practise meditation, read religious books, practise art and seek rest in nature). In particular, the percentage of people practising art (2018, 10.7\%; 2019, 16.4\%; $2020,37.9 \%)$ and seeking rest in nature daily $(2018,27.6 \%$; 2019, 25.5\%; $2020,52.6 \%$ increased significantly. Regarding the "Engage in voluntary work" category, daily practice did not increase, although a lower percentage of students in 2020 choose the answer "Never" (2018, 28.2\%; 2019, 27.3\%; 2020, 19.3\%). The percentage of nursing students visiting religious places/ meetings is almost the same in all three groups. Table 2 illustrates the three groups' spiritual practices.

\section{Significant Life Events}

In $2018,39 \%$ of the students had experienced significant life events (30\% positive and $30 \%$ negative), while $54.5 \%$ had not experienced any significant life events (6.5\% did not answer). Similarly, in 2019, 44.6\% had experienced significant life events (26.8\% positive and $33.9 \%$ negative), $50 \%$ had not experienced any significant life events and $5.4 \%$ did not answer. These numbers were only slightly different in 2020 , with $37.9 \%$ experiencing significant life events (20.7\% positive and $31 \%$ negative), $60.3 \%$ not experiencing any significant life events and $1.7 \%$ not answering. Table $3 \mathrm{a}$ and $3 \mathrm{~b}$ demonstrate a list of surveyed significant life events and their distribution among the three groups.

\section{Self-Assessment Tools}

JAREL

For the 2018 group, $56 \%(n=43)$ of students reached a sum score indicating medium spiritual well-being, and $44 \%(n=34)$ reached a score of between 85 and 126, demonstrating high spiritual well-being. None of the students were in the category "low well-being". These numbers were similar for the 2019 group, with $55.3 \%(n=31)$ scoring in the medium well-being range, 42.9\% $(n=24)$ indicating high well-being, and one student $(1.8 \%)$ scoring in the low well-being range. The JAREL scores for the 2020 group, however, differ from the other two. A total of $17.2 \%(n=10)$ reported low well-being, $82.8 \%(n=48)$ scored in the medium well-being range, and none of the students reached scores in the high well-being range. 
Table 2

Spiritual practices

\begin{tabular}{|c|c|c|c|}
\hline Practise prayer & 2018 & 2019 & 2020 \\
\hline Daily & $3.9 \%(n=3)$ & $9.1 \%(n=5)$ & $10.3 \%(n=6)$ \\
\hline Weekly & $5.3 \%(n=4)$ & $12.7 \%(n=7)$ & $8.6 \%(n=5)$ \\
\hline Monthly & $14.5 \%(n=11)$ & $16.4 \%(n=9)$ & $17.2 \%(n=10)$ \\
\hline Less than monthly & $40.8 \%(n=31)$ & $34.5 \%(n=19)$ & $39.7 \%(n=23)$ \\
\hline Never & $35.5 \%(n=27)$ & $27.3 \%(n=15)$ & $24.1 \%(n=14)$ \\
\hline Practise meditation & 2018 & 2019 & 2020 \\
\hline Daily & $1.4 \%(n=1)$ & $0 \%$ & $3.4 \%(n=2)$ \\
\hline Weekly & $4.1 \%(n=3)$ & $7.3 \%(n=4)$ & $13.8 \%(n=8)$ \\
\hline Monthly & $6.8 \%(n=5)$ & $14.5 \%(n=8)$ & $10.3(n=6)$ \\
\hline Less than monthly & $14.9 \%(n=11)$ & $25.5 \%(n=14)$ & $19 \%(n=11)$ \\
\hline Never & $73 \%(n=54)$ & $52.7 \%(n=29)$ & $53.4 \%(n=31)$ \\
\hline Read religious books & 2018 & 2019 & 2020 \\
\hline Daily & $0 \%$ & $0 \%$ & $3.4 \%(n=2)$ \\
\hline Weekly & $0 \%$ & $0 \%$ & $1.7 \%(n=1)$ \\
\hline Monthly & $2.6 \%(n=2)$ & $0 \%$ & $1.7 \%(n=1)$ \\
\hline Less than monthly & $10.5 \%(n=8)$ & $21.8 \%(n=12)$ & $20.7 \%(n=12)$ \\
\hline Never & $85.7 \%(n=66)$ & $78.2 \%(n=43)$ & $72.4 \%(n=42)$ \\
\hline Visit religious places & 2018 & 2019 & 2020 \\
\hline Daily & $0 \%$ & $0 \%$ & $0 \%$ \\
\hline Weekly & $5.2 \%(n=4)$ & $0 \%$ & $7 \%(n=4)$ \\
\hline Monthly & $18.2 \%(n=14)$ & $23.6 \%(n=13)$ & $17.5 \%(n=10)$ \\
\hline Less than monthly & $49.4 \%(n=38)$ & $61.8 \%(n=34)$ & $57.9 \%(n=33)$ \\
\hline Never & $27.3 \%(n=21)$ & $14.5 \%(n=8)$ & $17.5 \%(n=10)$ \\
\hline Practise art & 2018 & 2019 & 2020 \\
\hline Daily & $10.7 \%(n=8)$ & $16.4 \%(n=9)$ & $37.9 \%(n=22)$ \\
\hline Weekly & $40 \%(n=30)$ & $36.4 \%(n=20)$ & $32.8 \%(n=19)$ \\
\hline Monthly & $17.3 \%(n=13)$ & $14.5 \%(n=8)$ & $12.1 \%(n=7)$ \\
\hline Less than monthly & $14.7 \%(n=11)$ & $16.4 \%(n=9)$ & $13.8 \%(n=8)$ \\
\hline Never & $17.3 \%(n=13)$ & $16.4 \%(n=9)$ & $3.4 \%(n=2)$ \\
\hline Seek rest in nature & 2018 & 2019 & 2020 \\
\hline Daily & $27.6 \%(n=21)$ & $25.5 \%(n=14)$ & $52.6 \%(n=30)$ \\
\hline Weekly & $50 \%(n=38)$ & $52.7 \%(n=29)$ & $40.4 \%(n=23)$ \\
\hline Monthly & $15.8 \%(n=12)$ & $14.5 \%(n=8)$ & $1.8 \%(n=1)$ \\
\hline Less than monthly & $3.9 \%(n=3)$ & $7.3 \%(n=4)$ & $5.3 \%(n=3)$ \\
\hline Never & $2.6 \%(n=2)$ & $0 \%$ & $0 \%$ \\
\hline Engage in voluntary work & 2018 & 2019 & 2020 \\
\hline Daily & $1.3 \%(n=1)$ & $1.8 \%(n=1)$ & $1.8 \%(n=1)$ \\
\hline Weekly & $11.8 \%(n=9)$ & $20 \%(n=11)$ & $14 \%(n=8)$ \\
\hline Monthly & $23.7 \%(n=18)$ & $10.9 \%(n=6)$ & $26.3 \%(n=15)$ \\
\hline Less than monthly & $25 \%(n=19)$ & $40 \%(n=22)$ & $38.6 \%(n=22)$ \\
\hline Never & $28.2 \%(n=29)$ & $27.3 \%(n=15)$ & $19.3 \%(n=11)$ \\
\hline
\end{tabular}

() Equinox Publishing Ltd 2021 
Table 3a

Significant positive life events

\begin{tabular}{llll}
\hline Positive life events & 2018 & 2019 & 2020 \\
\hline In total & 34 & 27 & 19 \\
Birth of relatives & $14.71 \%(n=5)$ & $3.70 \%(n=1)$ & $15.79 \%(n=3)$ \\
Relationships & $32.35 \%(n=11)$ & $29.63 \%(n=8)$ & $31.58 \%(n=6)$ \\
New flat/house/moving out from parents & $14.71 \%(n=5)$ & $14.81 \%(n=4)$ & $10.53 \%(n=2)$ \\
Working abroad/travelling & $11.76 \%(n=4)$ & $11.11 \%(n=3)$ & $10.53 \%(n=2)$ \\
Education/job & $11.76 \%(n=4)$ & $18.52 \%(n=5)$ & $15.79 \%(n=3)$ \\
Pets & $0 \%$ & $11.11 \%(n=3)$ & $5.26 \%(n=1)$ \\
Spirituality & $2.94 \%(n=1)$ & $3.70 \%(n=1)$ & $5.26 \%(n=1)$ \\
Other & $11.76 \%(n=4)$ & $7.41 \%(n=2)$ & $5.26 \%(n=1)$ \\
\hline
\end{tabular}

Table 3b

Significant negative life events

\begin{tabular}{llll}
\hline Negative life events & 2018 & 2019 & 2020 \\
\hline In total & 27 & 29 & 17 \\
Illness/health issues & $25.93 \%(n=7)$ & $24.14 \%(n=7)$ & $5.88 \%(n=1)$ \\
Death & $62.96 \%(n=17)$ & $51.72 \%(n=15)$ & $64.71 \%(n=11)$ \\
Divorce/separation & $11.11 \%(n=3)$ & $10.34 \%(n=3)$ & $11.76 \%(n=2)$ \\
COVID-19 & $0 \%$ & $0 \%$ & $5.88 \%(n=1)$ \\
Other & $0 \%$ & $13.79 \%(n=4)$ & $11.76 \%(n=2)$ \\
\hline
\end{tabular}

SAIL

In $2018,64.9 \%$ of the students achieved a mean scale score $>4$ (range 77-141), indicating high spiritual attitude/involvement. The mean scale score for the whole group was 4.14 and the mean sum score was 107.86. In a similar fashion, for the 2019 group, $64.3 \%$ had a mean scale score of 4.16 (range 81-141, mean sum score (whole group) $=108.21$ ). For the 2020 group, the percentage of students scoring 4.2 rose to $70.7 \%$ (range 64-144, mean sum score (total group) $=109.22$ ). On average, all three groups show rather high levels of spiritual attitude/involvement.

\section{SSCRS}

The 2018 group reached a mean sum score of 62.7 (range 44-77) and a group mean scale score of 3.69 (range 2.59-4.53). These numbers are similar to the 2019 group. The 2020 mean sum score is 61.48 (range 42-77), with a mean scale score of 3.62 (range 2.47-4.53). The numbers for the 2020 group, 
however, also differ with regard to the SSCRS scale. The 2020 group mean sum score is 65.93 (range 43-77), with a mean scale score of 3.88 (range $2.53-4.53$ ), indicating that the students in the 2020 group have a broader view of spirituality.

\section{SCCS}

In the 2018 group, the mean sum score was 93.53 (range 71-116). The SCCS score across all questions ranged from 2.63 to 4.30 , while $50.6 \%$ of the students reached a score $>3.5$, indicating a high level of perceived competency. For the 2019 group, the mean sum score reached 93.16 (range 59-135). A total of $44.6 \%$ reached a score $>3.5$, indicating a high level of perceived competency. Overall, the 2018 group had a mean SCCS score of 3.46, not quite reaching the cut-off value of 3.5. The same is true for the 2019 group, only reaching a mean SCCS score of 3.45. The value for the 2020 group also differed for the SCCS. In $60.3 \%$ of the 2020 group (mean sum score 94.52 , range 55-126), the SCCS score across all the questions ranged from 2.04 to 4.67 , while $60.3 \%$ scored $>3.5$ and achieved the high level of perceived competency range. Overall, the 2020 group had a mean SCCS score of 3.5. In other words, they exactly scored the value of 3.5, indicating a high level of perceived spiritual competence at group level.

\section{Discussion}

Kuven and Giske (2019) have stated that it is important but challenging to equip nursing students with the spiritual care competencies necessary to meet the standard set by the International Council of Nursing (Kuven \& Giske, 2019). An Austrian law from 2008 (\$3(2) Abs. 6 FH-GuK-AV) concerning the curriculum of undergraduate nursing education at universities of applied sciences states that graduates should be able to consider patients' spiritual needs while conducting interventions (Schwamberger, Biechl \& Habel, 2008). This statement is in accordance with the internationally acknowledged Code of ethics for nurses (ICN, 2012). Spirituality, spiritual care or spiritual needs, however, are mentioned neither in the Austrian Nursing Care Act (GuKG, 2018), nor in the training regulations for undergraduate nurses (GuK-AV, 2010). Evidently, when it comes to nurses' competencies, a major gap needs to be bridged between expectations and the status quo. Additional steps are needed to introduce spirituality and spiritual care competencies into undergraduate nursing curricula. This study demonstrates that regular assessment of students' perceptions, well-being 
and self-perceived competencies is equally essential in a spiritual care education context.

All three cohorts involved in our study were very homogeneous. Most of the participants in all three groups were female, between 21 and 25 years old, and described their "life view" as Christian (2018, 83\%; 2019, 72.7\%; $2020,75.9 \%)$. In light of all the participants being undergraduate nursing students, the results regarding age and gender make sense. The Christian life view in this sample is above average for Austria. Mohr (2020) states that in 2018, there were 4.98 million (57\%) Catholic and 285.128 (3.3\%) evangelical denominations in Austria. An additional 8\% of the Austrian population is declared Muslim, which is heavily underrepresented in all three sample years $(2018,1.3 \%, n=1 ; 2019,1.8 \%, n=1 ; 2020,1.7 \%, n=1)$. This discrepancy could be due to the still prevalent social inequities in Austria, especially in the field of higher education (Kristen, 2018).

In our survey, we asked our students to describe their daily spiritual practices. The results demonstrate that the percentage of daily spiritual practice of the students from the 2020 group increased in almost every category (practise prayer, practise meditation, read religious books, practise art and seek rest in nature). In particular, the percentage of students practising art $(2020,37.9 \% ; 2019,16.4 \% ; 2018,10.7 \%)$ or seeking daily rest in nature $(2020,52.6 \%, 2019,25.5 \% ; 2018,27.6 \%)$ increased significantly. Although the daily level of voluntary work engaged in did not increase in 2020, it is still noteworthy that a lower percentage of students chose the answer "Never" for doing voluntary work $(2020,19.3 \%$; 2019, 27.3\%; 2018, 28.2\%). One reason for the higher percentage of daily spiritual practice during the COVID19 lockdown could be a greater need for spirituality, to express and seek meaning, purpose and transcendence (EPICC, 2019). Another reason could be that the students had more time for daily spiritual practices. Although there was a greater demand on the nursing profession during the COVID-19 lockdown in spring 2020, nursing students were less affected by this.

Focusing on the self-assessment tools, all three groups show on average high levels of spiritual attitude and involvement (SAIL). In contrast, on the JAREL well-being scale, all three groups have different results. In 2020 , the spiritual well-being of students was much lower than in the previous years, and an alarming $17.2 \%$ scored low on spiritual well-being (vs $0 \%$ in 2018 and $1.8 \%$ in 2019). Keeping in mind that spiritual practices are carried out most often by this group, this outcome is of particular interest, confirming the lack of and, hence, greater need for spirituality. One explanation could be the COVID-19 pandemic and its associated lockdown measures, but further research is needed to confirm this assumption. In the study by Ross and co-workers (2014), most of the students reported high 
(71.9\%) or medium (28.1\%) spiritual well-being, without any ratings in the low category. Compared with international data, the results of all three Austrian groups regarding spiritual well-being are lower. Especially in the 2020 group, $17.2 \%(n=10)$ reported low spiritual well-being, $82.8 \%(n=48)$ medium well-being, and none of the students attained scores in the high spiritual well-being range.

Regarding the Spirituality and Spiritual Care Rating Scale (SSCRS) (McSherry, Draper \& Kendrick, 2002), all three groups achieved similar scores. The 2020 group reached the highest scores, indicating a broader view of spirituality (Ross et al., 2014). The students of 2020 also scored highest in the Spiritual Care Competency Scale (SCCS), which measures students' selfperception regarding their competence in delivering spiritual care $(60.3 \%$ vs $50.6 \%$ (2018) and $44.6 \%(2019))$. In addition, the overall group had a mean SCCS score of 3.5, indicating a high level of perceived competence (Ross et al., 2014), while the other two groups fell below the threshold of 3.5 (3.46 in 2018 and 3.45 in 2019).

The results indicate that the group of 2020 included students with the highest percentage of daily spiritual practice. These students show a high level of spiritual attitude and involvement, a higher level of perceived competence regarding delivering spiritual care and a broader view of spirituality than the other two groups; however, it is also the group with the lowest spiritual well-being scores. Our findings indicate that the COVID-19 pandemic lockdown has had a substantial impact on the spiritual well-being of our nursing students. Monitoring students' overall well-being is essential for nurses' personal development in terms of their self-care capacity. The educators need to establish strategies to provide nurses with tools for self-care, as their willingness to meet patients' needs remains high.

\section{Implications for Teaching Spirituality and Spiritual Care Online}

A survey conducted in 2015 demonstrated that only 3\% of spiritual care courses took place online (Paal, Leget \& Goodhead, 2015b). In 2020, we provided both teaching and self-assessment online. The pandemic necessitated this change, which allowed us to compare large class teaching with online teaching. From the beginning, we planned our course as a theoretical introduction to spirituality, including short lectures for input, group work on literature, self-assessment and polling for discussion. It contained several assignments that students were to conduct online. In 2020, all these tasks were online. All the exercises and tools, such as polls, discussion forums and the wikis for the group work were all in the same place. The impression was that students were more engaged during online lectures than during a 
six-hour classroom session with more than a hundred students. That might be one of the reasons why the scores on the perception of spirituality are broader in this group.

\section{Limitations of the Study}

We were not able to finish this study as planned and conducted in the previous years. In 2018 and 2019, the lecture was an in-class lecture, and the self-assessment tool was available in print format. In 2020, the teaching and self-assessment were provided online, which may have impacted students' response behaviour. Language may have been another factor, as the questionnaire was drafted in English, which may have increased the number of students unable to complete the self-assessment, leading to a decline in their participation in the study.

\section{Conclusion}

Students argue that spirituality and spiritual care are an integral part of professional nursing, which should serve as an indicator to educators, academic leaders and nursing associations to include the topic in further discussions.

The findings of our study indicate that during the COVID-19 lockdown students suffered from low spiritual well-being. It remains unclear whether the COVID-19 pandemic will have any long-term effects, and whether it is the only reason for such outcomes. If nurses are to educate people to manage their own health, including educating patients about the importance of spirituality and spiritual care, nurses' self- and healthcare practices need much more attention. Even if the students of 2020 and the previous years rated their competencies in delivering spiritual care as high, their care giving may be affected if their own spiritual well-being remains low for an extended period of time.

\section{Acknowledgments}

The authors thank the EPICC Network for their selfless support throughout this project. Appreciation is also expressed to Dr. Lindsay Carey (Palliative Care Unit, La Trobe University, Melbourne, Australia) for his editorial assistance.

Declaration of conflicting interests: the authors have no conflicts of interest to declare. 
Funding information: this work received no specific grant from any funding agency in the public, commercial or not-for-profit sectors.

\section{References}

Chuengsatiansup, K. (2003). Spirituality and health: An initial proposal to incorporate spiritual health in health impact assessment. Environmental Impact Assessment Review, 23, 3-15. https://doi.org/10.1016/S0195-9255(02)00037-9

EPICC (2019). Enhancing nurses' and midwives' competence in providing spiritual care through innovative education and compassionate care. Draft Spiritual Care Education Standard (Online). Retrieved 29 January 2021 from https://blogs.staffs.ac.uk/epicc/ files/2019/02/EPICC-Standard-final.pdf

Gesundheits- und Krankenpflege-Ausbildungsverordnung (GuK-AV) (2010). BGBl. II Nr. 179/1999 i.d.F. BGBl. II. Nr. 296/2010. Retrieved 29 January 2021 from http://www.ratg. at/gesetze/gesetz/GuK-AV/10011179

Gesundheits- und Krankenpflegegesetz (GuKG) (2018). BGBl. I Nr. 108/1997 i.d.F. BGBl. I Nr. 59/2018. Retrieved 29 January 2021 from https://www.jusline.at/gesetz/gukg

Ghorbani, M., Mohammadi, E., Aghabozorgi, R., \& Ramezani, M. (2021). Spiritual care interventions in nursing: An integrative literature review. Supportive Care in Cancer, 29, 1165-1181. https://doi.org/10.1007/s00520-020-05747-9

Hungelmann, J., Kenkelrossi, E., Klaasen, L., \& Stollenwerk, R. (1996). Focus on spiritual well-being: Harmonious interconnectedness of mind-body-spirit - use of the JAREL Spiritual Well-Being Scale - assessment of spiritual well-being is essential to the health of individuals. Geriatric Nursing, 17, 262-266. https://doi.org/10.1016/ S0197-4572(96)80238-2

ICN (2012). The ICN code of ethics for nurses. International Council of Nurses (Online). Geneva, Switzerland. https://www.icn.ch/sites/default/files/inline-files/2012_ICN Codeofethicsfornurses_\%20eng.pdf [Accessed 27.03.2019].

Kristen, C. (2018). Migrationsspezifische Ungleichheiten im deutschen Hochschulbereich. Journal for Educational Research Online, 6(2014)2, 113-134. https://doi. org/10.1007/978-3-658-04322-3_15

Kuven, B. M., \& Giske, T. (2019). Talking about spiritual matters: First year nursing students' experiences of an assignment on spiritual conversations. Nurse Education Today, 75, 53-57. https://doi.org/10.1016/j.nedt.2019.01.012

McSherry, W., Draper, P., \& Kendrick, D. (2002). The construct validity of a rating scale designed to assess spirituality and spiritual care. International Journal of Nursing Studies, 39(7), 723-734. https://doi.org/10.1016/S0020-7489(02)00014-7

Meezenbroek, E. D. J., \& Garssen, B. (2008). A multi-dimensional spirituality questionnaire, suited for use among religious and non-religious people. Psycho-Oncology, 17, S104S105. https://doi.org/10.4236/psych.2012.31017

Mohr, M. (2020). Statistiken zur Religion in Österreich. Retrieved 15 September 2020 from https://de.statista.com/themen/2066/religion-in-oesterreich

Paal, P., Helo, Y., \& Frick, E. (2015a). Spiritual care training provided to healthcare professionals: A systematic review. Journal of Pastoral Care \& Counseling, 69(1), 19-30. https:// doi.org/10.1177/1542305015572955

Paal, P., Leget, C., \& Goodhead, A. (2015b). Spiritual care education: Results from an EAPC survey. European Journal of Palliative Care, 22(2), 91-95. http://www.haywardpublishing. co.uk/NeedRegister.aspx?pageid $=58 \& J I D=4 \&$ Year $=2015 \&$ Edition $=533$

Paal, P., Neenan, K., Muldowney, Y., Brady, V., \& Timmins, F. (2018). Spiritual leadership as 
an emergent solution to transform the healthcare workplace. Journal of Nursing Management, 26, 335-337. https://doi.org/10.1111/jonm.12637

Peng-Keller, S., \& Rettke, H. (2017). Spiritual Care und Pflegewissenschaft. Ein Beitrag zum aktuellen Diskussionsstand im deutschsprachigen Raum. Spiritual Care, 6(4), 405-410. https://doi.org/10.1515/spircare-2017-0023

Ramezani, M., Ahmadi, F., Mohammadi, E., \& Kazemnejad, A. (2014). Spiritual care in nursing: A concept analysis. International Nursing Review, 61, 211-219. https://doi. org/10.1111/inr.12099

Ross, L., van Leeuwen, R., Baldacchino, D., Giske, T., McSherry, W., Narayanasamy, A., Downes, C., Jarvis, P., \& Schep-Akkerman, A. (2014). Student nurses' perceptions of spirituality and competence in delivering spiritual care: A European pilot study. Nurse Education Today, 34, 697-702. https://doi.org/10.1016/j.nedt.2013.09.014

Ross, L., Giske, T., van Leeuwen, R., Baldacchino, D., McSherry, W., Narayanasamy, A., Jarvis, P., \& Schep-Akkerman, A. (2016). Factors contributing to student nurses'/midwives' perceived competency in spiritual care. Nurse Education Today, 36, 445-451. https://doi.org/10.1016/j.nedt.2015.10.005

Ross, L., McSherry, W., Giske, T., van Leeuwen, R., Schep-Akkerman, A., Koslander, T., Hall, J., Steenfeldt, V. O., \& Jarvis, P. (2018). Nursing and midwifery students' perceptions of spirituality, spiritual care, and spiritual care competency: A prospective, longitudinal, correlational European study. Nurse Education Today, 67, 64-71. https://doi. org/10.1016/j.nedt.2018.05.002

Schwamberger, H., Biechl, R., \& Habel, N. (2008). FH-Gesundheits- und Krankenpflege-Ausbildungsverordnung (FH-GuK-AV), BGBI. II Nr. 200/2008. Verlag Österreich. Retrieved 29 January 2021 from https://elibrary.verlagoesterreich.at/book/99.105005/9783704681751

van Leeuwen, R., Tiesinga, L. J., Middel, B., Post, D., \& Jochemsen, H. (2009). The validity and reliability of an instrument to assess nursing competencies in spiritual care. Journal of Clinical Nursing, 18, 2857-2869. https://doi.org/10.1111/j.1365-2702.2008.02594.x 